\title{
THE MAKING OF AN EXTREME EVENT Putting the Pieces Together
}

by Randall Dole, Martin Hoerling, Arun Kumar, Jon Eischeid, Judith Perlwitz, Xiao-Wei Quan, George Kiladis, Robert Webb, Donald Murray, Mingyue Chen, Klaus Wolter, and Tao Zhang

\author{
Record warm temperatures over the United States in March 2012 \\ were mostly due to natural climate and weather variability.
}

N ature's exuberant smashing of high temperature records in March 2012 can only be described as "Meteorological March Madness." The numbers were stunning. During much of the month, conditions more fitting of June than March prevailed east of the Rocky Mountains. For example, Chicago set daily high temperature records on nine consecutive days during 14-22 March. Eight of those days saw the mercury eclipse $80^{\circ} \mathrm{F}\left(26.7^{\circ} \mathrm{C}\right)$ - a value for average daily highs not reached until after the summer solstice. At the peak of the event, daily mean temperatures in some locations reached more than $40^{\circ} \mathrm{F}\left(22^{\circ} \mathrm{C}\right)$ above normal. With the exceptional warmth, early blooming

AfFiliations: Dole, HoERLING, KILADIS, AND WebB-NOAA/ Earth System Research Laboratory, Boulder, Colorado; Kumar ANd Chen-NOAA/Climate Prediction Center, Camp Springs, Maryland; Eischeid, Perlwitz, Quan, Murray, Wolter, AND ZHANG - NOAA/Earth System Research Laboratory, and Cooperative Institute for Research in Environmental Sciences, University of Colorado, Boulder, Boulder, Colorado CORRESPONDING AUTHOR: Martin Hoerling, NOAA/Earth System Research Laboratory, 325 Broadway, Boulder, CO 80305 E-mail: martin.hoerling@noaa.gov

The abstract for this article can be found in this issue, following the table of contents.

DOI:10.1175/BAMS-D-12-00069.1

A supplement to this article is available online (10.1175/BAMS-D-12-00069.2)

In final form 26 June 2013

C2014 American Meteorological Society of trees, flowers, and vegetation occurred over much of the nation east of the Rockies (Elwood et al. 2013). Major fruit crop losses were subsequently experienced in portions of the upper Midwest when freezing conditions returned in April (Allen 2012).

What are the primary physical processes that make an event extreme? Addressing this question is fundamental to understanding the causes of extreme events and to assessing their potential predictability. The answers are important for applications spanning a wide range of time scales, from providing early warning of extreme weather at short lead times to informing climate model development and climate adaptation strategies on longer time scales. In this study we examine evidence for contributions from various physical processes to the extreme warmth over the central and eastern United States in March 2012. This study follows the spirit of several recent articles in BAMS that emphasize the need to better understand climate and weather connections for improving Earth system predictions (e.g., Shapiro et al. 2010; Brunet et al. 2010). Here we describe how various pieces across the spectrum from climate to weather came together to produce the March 2012 extreme warm event.

CLIMATE OVERVIEW. To first put the record U.S. warm temperatures in a global context, National Climatic Data Center (NCDC) preliminary data indicate that March 2012 had a global-mean temperature of $0.46^{\circ} \mathrm{C}$ above the twentieth-century average, making it the 16th warmest March on record since 1895, 
but also the coolest globally since 1999 (www.ncdc .noaa.gov/sotc/global/20I2/3). For the global land surface temperature, NCDC's preliminary report shows March 2012 was $0.73^{\circ} \mathrm{C}$ above the twentiethcentury average-the 18th warmest over the same period. Concurrent with the extreme warm temperatures over the central and eastern United States, below normal temperatures prevailed over large portions of the northwestern United States, western Canada, Alaska, eastern Asia, and Australia, with warm anomalies present over western Europe and Scandinavia (Fig. 1a). Over the contiguous United States, the NCDC reported that 2012 was the warmest March on record over the period since 1895, with the average temperature $8.6^{\circ} \mathrm{F}\left(4.8^{\circ} \mathrm{C}\right)$ above the twentieth-century average. In the core of the affected region, monthly-mean anomalies were over $16^{\circ} \mathrm{F}$ $\left(9^{\circ} \mathrm{C}\right)$ above the climatological normals.

Both the United States and the global surface temperature pattern during March 2012 have historical precedent, bearing a strong resemblance to conditions observed over a century earlier, in March 1910 (Fig. 1b). Temperatures in 1910 were nearly as warm as in 2012 over the contiguous United States, with a mean departure in 1910 relative to the twentieth-

\section{a) March $2012 \mathrm{Tmp}$ Departures}

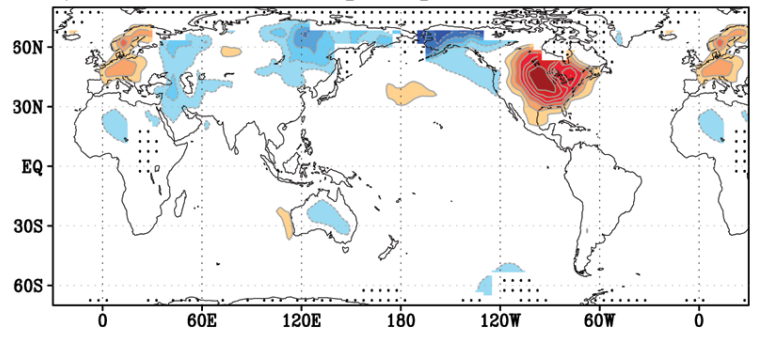

c) March Tmp Trend 1901-2011

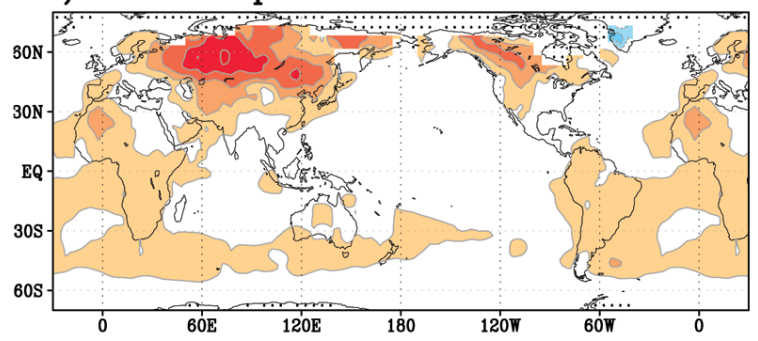

century average of $+4.5^{\circ} \mathrm{C}$ (compared to $+4.8^{\circ} \mathrm{C}$ in 2012). The global temperature patterns for both months, though separated by over a century, are also strikingly similar. Over North America, maximum warm anomalies in March 1910 and March 2012 occur from the Midwest and northern plains states northward into south-central Canada, with cold anomalies farther northwest over parts of western Canada and Alaska. Below normal temperatures are present in both 2012 and 1910 over large portions of eastern Asia and eastern Europe, with above normal temperatures over western Europe. The principal difference between March 2012 and March 1910 surface temperatures is in the global-mean value. Compared with March 1910, the global-mean temperature in March 2012 is $0.91^{\circ} \mathrm{C}$ warmer-consistent with a general increase in global-mean temperatures observed during the twentieth century that has been attributed mostly to human causes (Hegerl et al. 2007). It is noteworthy that not all regions have warmed at the same rate since the beginning of the twentieth century. In particular, the epicenter for the March 2012 event has experienced substantially less temperature rise than adjacent portions of western Canada and much of Eurasia (Fig. 1c).

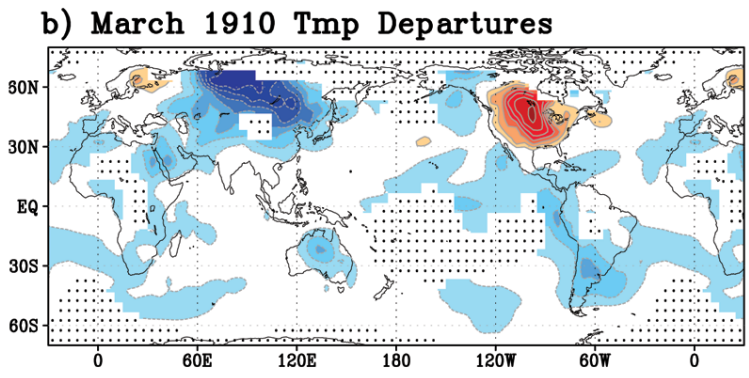

d) March 2012 Tmp (trend removed)

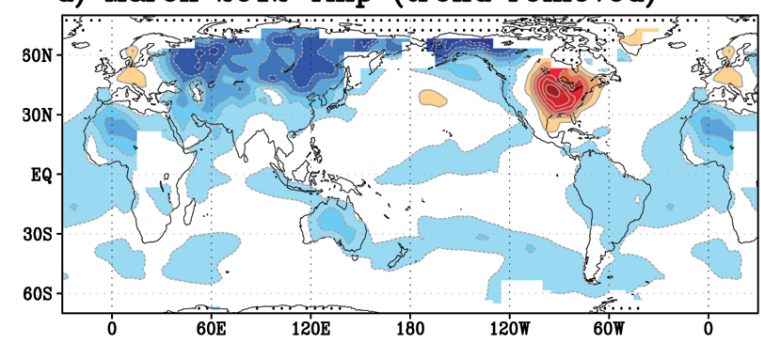

Degrees Celsius

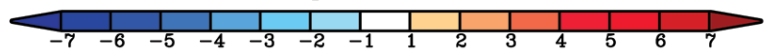

FIG. I. March surface temperature anomalies for (a) 2012 and (b) 1910. (c) Mar temperature change derived from the trend over the III-yr period 190I-20II. (d) Detrended Mar 2012 temperature anomalies (Units: ${ }^{\circ} \mathrm{C}$ ). Areas of insufficient data are indicated by stippling. Data are from the NCDC merged land-ocean dataset version $3 \mathrm{~b}$ (Smith et al. 2008). Anomalies are departures from means over a 198I-20I0 base period unless stated otherwise. 
A simple estimate of the event magnitude above the long-term warming trend can be obtained by subtracting the temperature changes estimated from the trend since 1901 from the March 2012 anomalies-an approach similar to that used in previous studies (e.g., Cattiaux et al. 2010; Ouzeau et al. 2011). The resulting detrended March 2012 temperature anomaly pattern is almost the same as March 1910 over the central United States as well as many other parts of the globe (Fig. 1d). Over parts of Eurasia where warming trends have been large, there is much more similarity between the detrended 2012 and 1910 patterns. However, over areas of the United States most affected by the extreme warmth there is little discernible difference between the detrended and original March 2012 patterns. This is because in these areas, the magnitude of the regional warming trend $\left(\sim 0.5^{\circ}-1^{\circ} \mathrm{C}\right)$ is approximately an order of magnitude smaller than the monthly temperature anomalies, which exceeded $9^{\circ} \mathrm{C}$ near the core of the maximum warmth. Overall, this result indicates that a superposition of a strong natural variation similar to March 1910 onto the observed long-term warming would be sufficient to account for the extreme magnitude of the March 2012 U.S. monthly-mean temperature anomalies.

In addition to longer-term trends, variability on seasonal-to-interannual time scales provides another important climate context for the March 2012 heat wave. The preceding winter (December-February) was characterized by La Niña conditions, with below normal sea surface temperatures (SSTs) over the central and eastern tropical Pacific and above normal SSTs over Indonesia, the western tropical Pacific, and the central North Pacific (Fig. 2a). Both the March 2012 and March 1910 U.S. extreme warm temperatures occurred in the second year of prolonged La Niña events (Wolter and Timlin 2011). The winter mean outgoing longwave radiation (OLR) anomalies preceding the March 2012 event indicate generally suppressed convection over the central Pacific and enhanced convection from the eastern Indian Ocean to over the Maritime Continent (Fig. 2b). As such, the March 2012 U.S. extreme warm temperatures occur in the immediate aftermath of a global climate state that has been perturbed by naturally occurring cooling of the tropical eastern Pacific Ocean, with an overall pattern of North Pacific SSTs resembling the negative phase of the Pacific decadal oscillation (Mantua et al. 1997).

\section{METEOROLOGICAL CONDITIONS AND ASSOCIATED PROCESSES. The general timing} and the maximum daily warmth associated with the March 2012 event is revealed by time series of surface station observations, for which Minneapolis, Minnesota, provides a representative example (Fig. 3). A steplike onset of extreme warmth commences on 10 March, with temperature departures going from slightly below normal to over $11^{\circ} \mathrm{C}\left(20^{\circ} \mathrm{F}\right)$ above 
normal in one day. The rapid onset indicates the strong contribution of synoptic-scale processes to the event. Daily-mean temperature anomalies in Minneapolis reached a remarkable $20.6^{\circ} \mathrm{C}\left(37^{\circ} \mathrm{F}\right)$ above normal on $17 \mathrm{March}$, with three consecutive days of $+20^{\circ} \mathrm{C}$ departures. Farther east, the sudden warm spike occurs a few days later. The period of maximum intensity in the Midwest spans roughly 12-23 March, over which we will present time-averaged analyses. A comparison with the 1910 time series [Fig. ES1; supplemental figures can be viewed online (doi:10.1175/ BAMS-D-12-00069.2)] indicates that the 1910 event had qualitatively similar behavior, although with lower peak values and slightly longer duration.

An important synoptic feature is the depth of the anomalously warm air through the troposphere. The time-averaged surface and $850-\mathrm{hPa}$ temperature anomalies during 12-23 March (Figs. 4a,b, left) display highly similar patterns and magnitudes. Maxima exceeding $+15^{\circ} \mathrm{C}$ occur over the Great Lakes region, with warm conditions extending across the

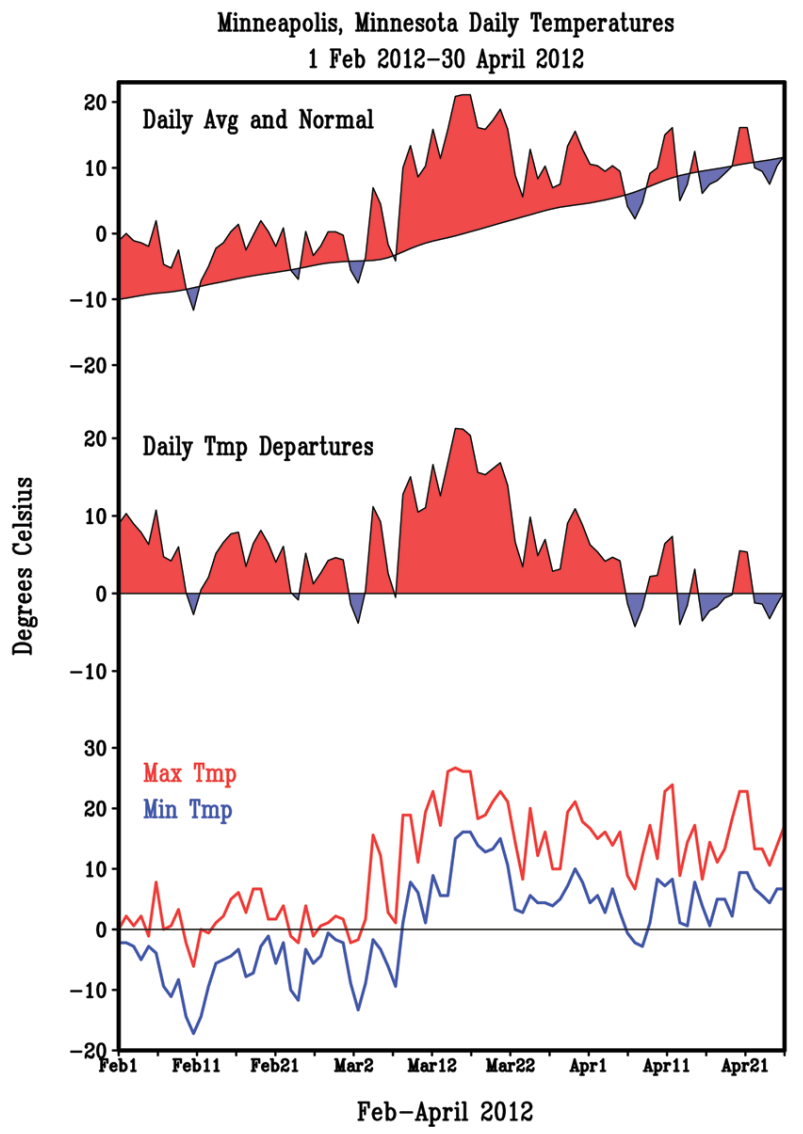

FIG. 3. (top) Daily average temperatures, (middle) daily departures, and (bottom) maximum and minimum temperatures for Minneapolis, Minnesota, from Feb to Apr $2012\left({ }^{\circ} \mathrm{C}\right)$. Temperature data are from the Global Daily Climatology Network.
United States east of the Rockies on a scale identical to the surface warmth. During this period $850-\mathrm{hPa}$ vector wind anomalies were strongly southerly across a corridor of the eastern Great Plains and Midwest from Louisiana to the Canadian Prairie (Fig. 4c, left), with anomalies at times exceeding $20 \mathrm{~m} \mathrm{~s}^{-1}$. These flow anomalies were directed nearly straight down the time-mean temperature gradient over this region. A rough estimate of the magnitude of the poleward heat transport can be inferred from the map of wind anomalies overlain on the climatological $850-\mathrm{hPa}$ temperatures (contours in Fig. 4c). The latter show approximately a $20^{\circ} \mathrm{C}$ mean temperature difference between the Gulf Coast and the northern Great Lakes area during March. Simple quasi-horizontal, adiabatic air mass transport would yield a roughly $20^{\circ} \mathrm{C}$ warming for such a displacement-a value close to the observed maximum 850-hPa temperature departures over the northern Great Lakes.

For comparison, the right panels show corresponding analyses from the Twentieth Century Reanalysis dataset (Compo et al. 2011) for a 12-day period in March 1910. There is considerable similarity in the primary features, although the maximum intensity is greater in 2012, largely reflecting a stronger transient peak in 2012 compared to 1910. Some of this difference may also be related to the more limited observations incorporated into the historical reanalysis for 1910. The key dynamical feature evident in both years is the strong anomalous anticyclonic circulation and resulting intense poleward heat transport, with the maximum temperature anomalies occurring near the northern end of the zone of strong transport.

The surface warming was strongly coupled to poleward warm air transport extending throughout the troposphere, as can be seen in vertical soundings over this period, such as the 0000 UTC 19 March sounding from Chanhassen (Minneapolis, KPMX), Minnesota (Fig. ES2). The general veering of winds with increasing height is consistent with warm advection-a condition inferred also from Fig. 4c. Evidence of vertical mixing is provided by the presence of steep, near dry-adiabatic lapse rates together with wind speeds near $20 \mathrm{~m} \mathrm{~s}^{-1}$ just above the surface-the latter conducive to vigorous mechanical turbulence. Back trajectory analyses for the previous $24 \mathrm{~h}$ (not shown) indicate air at 3000- and 5000-m levels over KMPX had descended while following northeastward trajectories originating from over southern New Mexico, whereas air parcels in the boundary layer (500 $\mathrm{m}$ above ground level) followed quasi-horizontal trajectories originating from around eastern Texas a day earlier. 
The key question then becomes what factors were primarily responsible for producing the anomalously strong, deep, and sustained southerly flow during this period? The time-mean 300-hPa height anomalies for the same period during March 2012 (Fig. 6, top panel) provide an important clue. The pattern shows an arching wave train of anomalies extending northward and eastward from the western tropical Pacific, with major anticyclonic centers just east of the date line and over the Great Lakes-the latter directly related to the extreme warm temperatures. This pattern is consistent with what would be expected for a Rossby wave response to anomalous tropical heating (e.g., Hoskins and Karoly 1981; Plumb 1985), though such features can also arise from energy dispersion from initial perturbations located in the subtropics and midlatitudes (e.g., Simmons et al. 1983). It also bears some resemblance to the wintertime North Pacific Oscillation-west Pacific teleconnection (Linkin and Nigam 2008) that varies on subseasonal time scales, for which extratropical synoptic-scale eddy forcing plays an important role.

The time evolution of the upper-level circulation antecedent to and during the event indicates appreciable transience-consistent with downstream energy dispersion from the western Pacific to North America (Fig. 5, right-hand side). In particular, strong ridge amplification occurs first over the central Pacific early in March, followed by trough deepening near the U.S. West Coast and then ridge amplification over the central and eastern United States. The latter feature is
March 18-March 291910
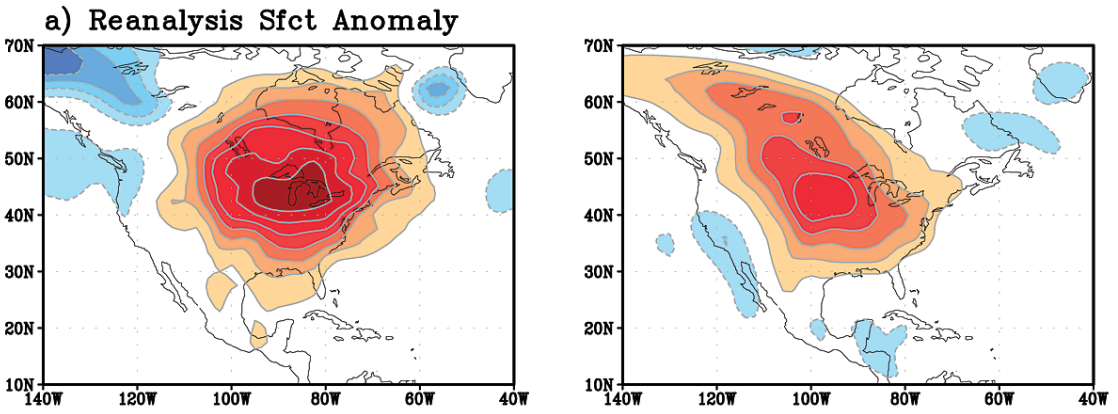

b) Reanalysis $850 \mathrm{mb} \mathrm{Tmp}$ Anomaly

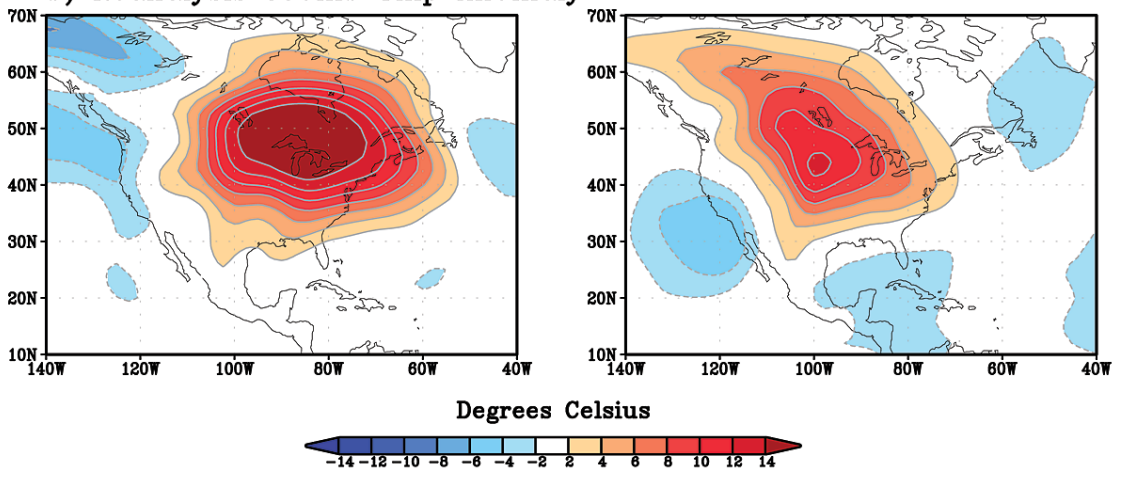

c) Reanalysis $850 \mathrm{mb} \mathrm{Tmp}$ Climo/850mb Winds

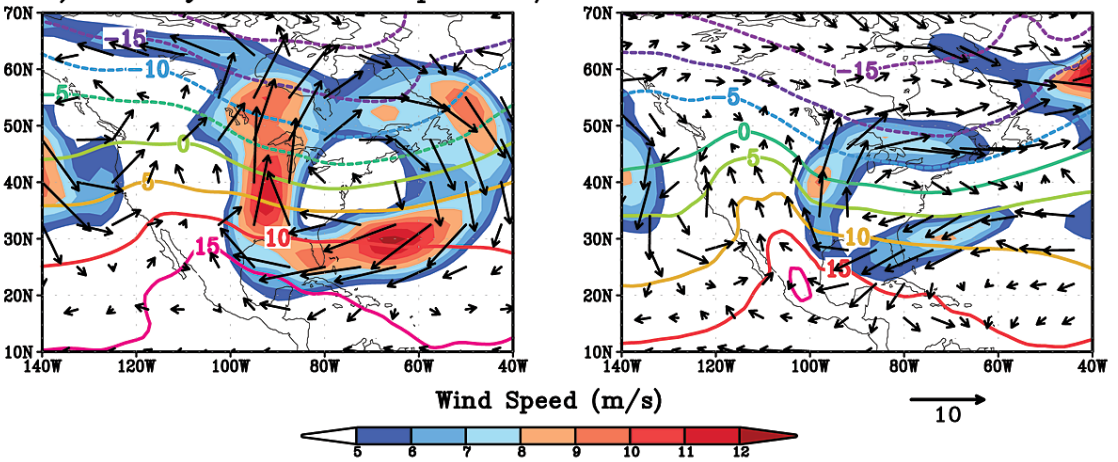

Fig. 4. (left) The I2-23 Mar 2012 time-mean (a) surface temperature anomalies ( $\left.{ }^{\circ} \mathrm{C}\right)$, (b) $850-\mathrm{hPa}$ temperature anomalies $\left({ }^{\circ} \mathrm{C}\right)$, and (c) $850-\mathrm{hPa}$ vector wind anomalies together with Mar climatological-mean 850-hPa temperatures $\left({ }^{\circ} \mathrm{C}\right)$. (right) Corresponding maps for 18-29 Mar 1910. Data for 2012 are derived from the NCEP-National Center for Atmospheric Research (NCAR) reanalysis (Kalnay et al. 1996) and for 1910 from the Twentieth Century Reanalysis Project (Compo et al. 20II). 
convection centered near $170^{\circ} \mathrm{E}$, just south of the equator during early March (Fig. ES3). The overall pattern is similar to that of the preceding winter mean (cf. Fig. 2b) but strongly enhanced, particularly over the eastern Indian Ocean and western Maritime Continent. This enhancement is directly related to a very strong Madden-Julian oscillation (MJO) propagating slowly eastward over this period, which reinforces the winter tropical convection pattern related to anomalous sea surface temperatures (Fig. 5, lefthand side). Beginning in late February a significant MJO was initiated over the central Indian Ocean, as seen in the OLR field. A large area of negative OLR anomalies amplifies rapidly during the last week of the month and then propagates eastward. The enhanced convective signal reaches the Maritime Continent around 10 March, concurrent with a suppressed convective signal just west of the date line. The amplitude of this MJO event exceeded two standard deviations of the Real-time Multivariate MJO (RMM) index of Wheeler and Hendon (2004) for much of the month of March. The unusually strong tropical heating anomalies extending from the Indian Ocean through the tropical western Pacific therefore provide a plausible source for forcing an amplified Rossby wave train as seen in March 2012.
To further examine evidence for such a linkage, we have conducted experiments with a linear baroclinic model (LBM) (Peng and Whitaker 1999; appendix A) forced by an idealized pattern of tropical heating anomalies similar to the observed pattern over the Indian and western Pacific Oceans and imposed on a climatological March basic state (Fig. 6c). The steady solution is approximated as the average of the last 5 days of a 60 -day integration. The observed $300-\mathrm{hPa}$ height pattern (Fig. 6a) and the response of the LBM to the forcing from the tropical heating anomalies (Fig. 6b) are highly similar over the period in which the U.S. warmth was at its peak, with a strong anticyclonic anomaly centered north of the Great Lakes. This supports the interpretation that tropical heating anomalies over the Indian Ocean and western Pacific contributed directly to the flow anomalies that were the proximate cause for the extreme warm temperatures in March 2012. The tropical heating anomalies in turn appear to be due to the constructive superposition of enhanced convection associated with an exceptionally strong MJO event occurring on subseasonal time scales with a similar seasonal convection pattern, with the latter closely related to SST anomalies over the tropical Pacific and Indian Ocean that included an ongoing La Niña.
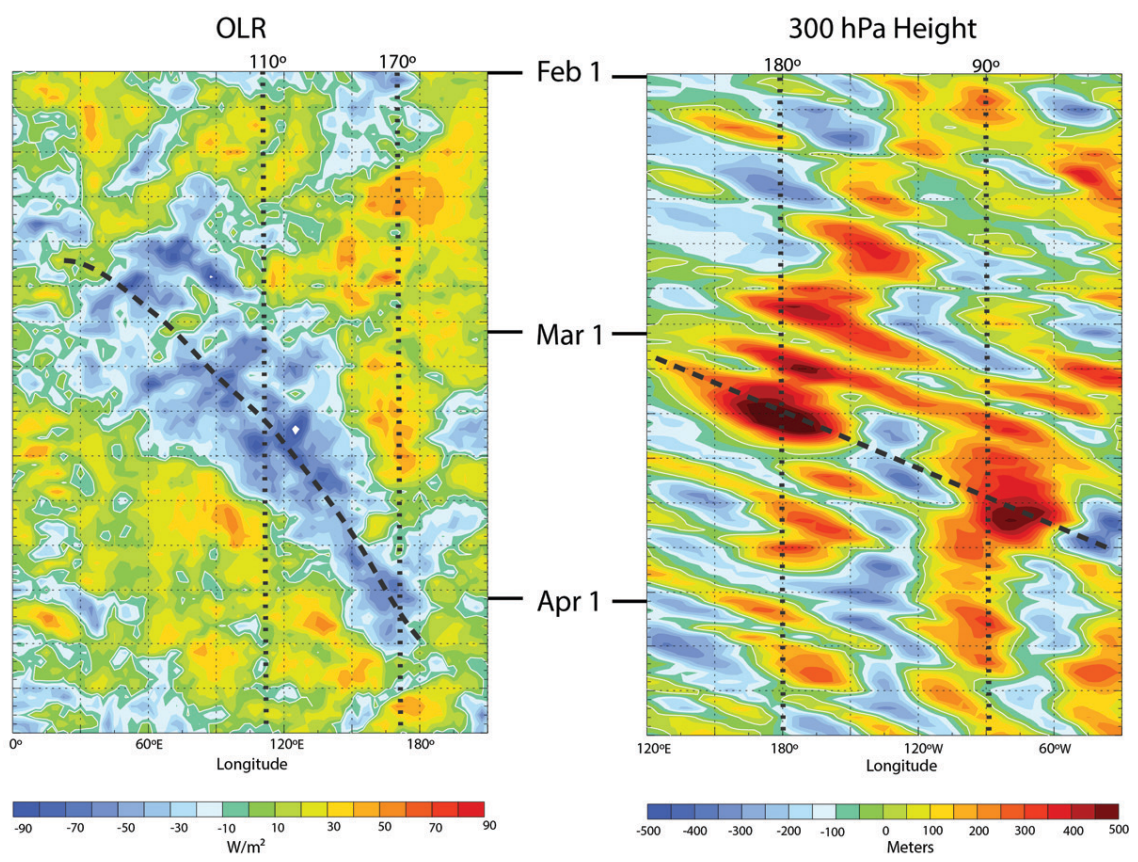

FIG. 5. Time-longitude analyses over the period I Feb-30 Apr 2012 of (a) OLR anomalies $\left(\mathrm{W} \mathrm{m}^{-2}\right)$ averaged over $5^{\circ} \mathrm{N}-5^{\circ} \mathrm{S}$ extending from West Africa to the east-central Pacific and (b) 300-hPa height anomalies (m) for a midlatitude band $\left(30^{\circ}-50^{\circ} \mathrm{N}\right)$ from East Asia to the eastern North Atlantic. The sloped dash lines depict in (a) the eastward propagating MJO convective signal and in (b) downstream energy dispersion from the Pacific to the North Atlantic.
ANTICIPATION. To what extent might extreme warmth of the magnitude of the March 2012 event been anticipated from prior climate conditions? One source of potential predictability arises from long-term warming, which at global and continental scales has been attributed mostly to increased greenhouse gas concentrations arising from human influences (Hegerl et al. 2007). Since 1900, the observed warming trend in March over the region affected by extreme warmth is approximately $1^{\circ} \mathrm{C}$ (cf. Fig. 1c). Following the approach of Hoerling et al. (2013), we have also estimated externally forced climate trends from an ensemble of 20 different coupled oceanatmosphere models used 
in phase 5 of the Coupled Model Intercomparison Project (CMIP5; see Taylor et al. 2012). Similar to summer results presented in Hoerling et al. (2013), as well as previous CMIP3 simulations (e.g., Dole et al. 2008), the CMIP5 ensemble-mean results show warming trends over all of the United States (Fig. ES4), with projected temperature increases relative to the models' 1981-2010 climatologies ranging from just over $1^{\circ} \mathrm{C}$ over the upper Midwest and northern plains to less than $0.5^{\circ} \mathrm{C}$ over the south and near the West and East Coasts.

Observations and models are therefore in rough agreement in suggesting that a temperature increase of up to approximately $1^{\circ} \mathrm{C}$ could be anticipated from the long-term warming trend, which in the CMIP5 results is mostly due to external forcing from increasing greenhouse gas concentrations. Compared to the observed peak event magnitude of approximately $20^{\circ} \mathrm{C}$, a $1^{\circ} \mathrm{C}$ increase is small. However, even a relatively modest increase in mean temperatures would increase the probability of exceeding any fixed temperature threshold, including record values, and would make the magnitude of any warm record incrementally larger (Stott et al. 2004; Meehl et al. 2009; Otto et al. 2012). Such foreknowledge would not, however, provide specific guidance as to when or where such an event would occur or how intense it might be.

It is also possible that there has been a trend toward larger variability from either natural or human causes that would increase the likelihood of an extreme event. To assess this possibility, changes in monthlymean and daily variability were examined over the period 1900-2012. Figure 7a shows a time series of monthly temperature departures for Wisconsin and Minnesota - two states in the epicenter of the extreme warmth. Visual inspection suggests that monthly-mean temperatures in the latter part of the record have been, if anything, less variable. Figure $7 \mathrm{~b}$ provides a more quantitative evaluation by showing the standard deviations of March temperatures about running 30-yr means from 1900 to present. Maximum variability occurs at the beginning of the record and minimum variability occurs near the end, declining from almost $3^{\circ} \mathrm{C}$ early to approximately $1.7^{\circ} \mathrm{C}$ for the 30 -yr period ending in 2011 -a decrease of well over $40 \%$. The change in temperature variability in this region appears fairly representative of most of the United States (Fig. ES5). Other fields, including 850-hPa heights and 850-hPa winds, also fail to show evidence of increasing variability (Fig. ES5). Over more recent multidecadal time periods, a similar 
analysis for daily variability within March shows little change over North America (Fig. ES6). Thus, neither daily nor monthly variability show evidence of increasing variability that might have increased the probability for an extreme temperature event. Indeed, a decline in variability as seen in monthly means would tend to decrease that probability (Katz and Brown 1992; Sardeshmukh et al. 2000).

Other physical factors that may have played a role in this case include land-atmosphere interactions related to anomalous snow cover. Rutgers University Global Snow Laboratory climatological data (available at http://climate.rutgers.edu/snowcover/) show that most areas of the central and eastern United States south of a line from around Chicago to Memphis are not normally snow covered in March. Thus, over much of the area experiencing record heat the absence of snow cover was unlikely to explain the extreme magnitude of the event. Over the far northern United States and Canada, the Rutgers data show near-normal snow extent at the beginning of March, with small negative anomalies by 10 March. Subsequently, intense warm advection with strong southerly winds resulted in rapid snow loss through melting and sublimation. Changes in the resulting surface heat balance likely amplified the strong surface warming over initially snow-covered regions. However, even in these areas snow cover anomalies were more a response to the exceptional warmth than the primary cause.

Other conditions, however, did provide early warning of the potential for extreme warm temperatures in the central and eastern United States in March 2012. Predictions from the National Oceanic and Atmospheric Administration (NOAA)/ National Centers for Environmental Prediction (NCEP) Climate Forecast System version 2 (CFSv2; NOAA's current operational model used for seasonal and subseasonal forecasts) (Saha et al. 2013; Fig. 8) show ensemble averages from CFSv2 predictions for March 2012 initialized in December 2011, January 2012, and February 2012. The December and January predictions show quite similar temperature patterns, with above normal temperatures predicted over the eastern United States and below normal temperatures over the northwestern United States, western Canada, and Alaska. This high degree of consistency largely reflects the model response to SSTs varying on seasonal-to-interannual time scales.

Predictions initialized in February, while sharing several common features, also show key changes from the earlier forecasts. In particular, the warmth over the United States intensifies considerably, expands in areal coverage, and shifts the epicenter of warm anomalies northwestward toward the upper Midwest-much closer to the pattern observed the following month. The predicted magnitude of the ensemble-mean temperature anomalies is approximately two standardized departures of the variability in model forecasts. Other significant changes between the February and earlier forecasts include marked intensification of precipitation over the Maritime Continent and stronger positive height anomalies with a more amplified ridge over the eastern United States.

Ensemble simulations with the atmospheric component of the NCEP CFSv2 model [Global Forecast System, version 2 (GFSv2)] forced only by observed monthly varying SSTs, sea ice, and $\mathrm{CO}_{2}$ reinforce the interpretation that specific boundary conditions for 2012 contributed to the exceptional warmth over the United States (simulation details are provided in appendix B). The ensemble-mean results show generally warm conditions extending from the southwestern United States over all of the eastern United States, with below normal temperatures over northwestern Canada and Alaska (Fig. 9a). An arcing wave train

Minnesota/Wisconsin March Temperature

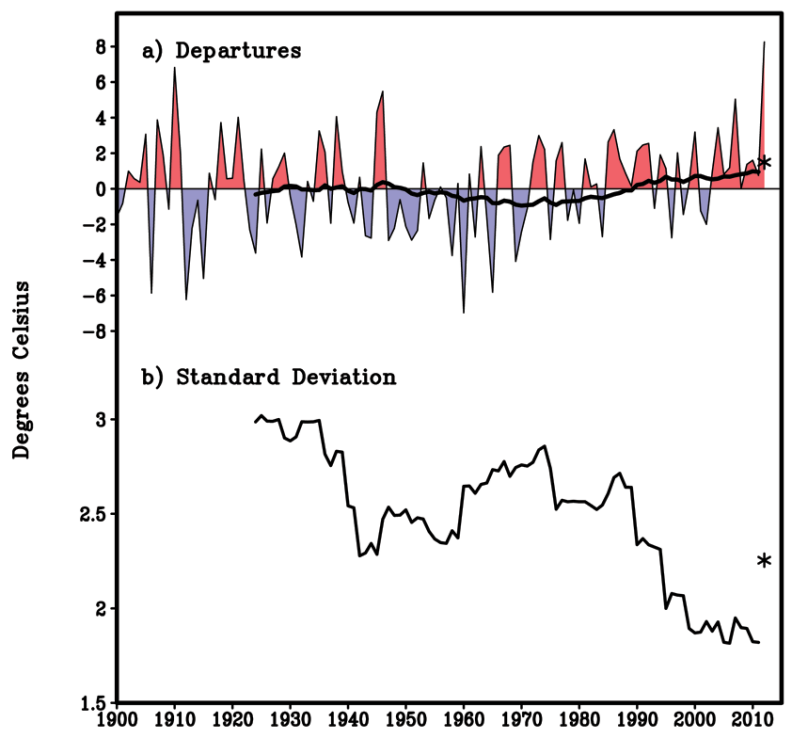

FIG. 7. Minnesota-Wisconsin area average (a) Mar temperature anomaly time series from 1900 to 2012 , along with 30 -yr running mean of this average plotted at the ending year, and (b) the standard deviation of the Mar area average temperatures about their 30-yr running means, plotted at the ending year $\left({ }^{\circ} \mathrm{C}\right)$. The asterisks denote the corresponding values for the $30-y r$ periods ending in 2012 , illustrating how the inclusion of Mar 2012 alters the statistics. From NCDC Climate Division data. Asterisks denote the values of the 30-yr mean and standard deviation for 1983-20I2. 
extending across the North Pacific over North America is once again evident in the $300-\mathrm{hPa}$ height anomalies (Fig. 9b). Both temperature and height anomalies resemble those seen in the CFS predictions initialized in December and January, especially the latter month (cf. Fig. 8). The temperature anomaly pattern is also similar to March 2012 over North America, although the largest warm anomalies in these simulations are displaced southwest relative to the observed pattern. Interestingly, the mean temperature and height anomalies in the simulations are not canonical La Niña patterns (Linkin and Nigam 2008), although the height pattern does resemble a Rossby wave response to tropical forcing from the western
Pacific (e.g., Karoly et al. 1989). The corresponding ensemble-mean patterns for March 2011 (not shown), which also had a La Niña event and virtually identical levels of $\mathrm{CO}_{2}$, show large differences in temperatures and heights over North America, with colder than normal conditions over the northern two-thirds of the United States and Canada and an intensified westerly jet across the central United States. These large differences indicate that considerable variations in atmospheric-forced responses can occur in different La Niña years, with important implications for climate predictions over North America and elsewhere.

The much stronger signal in the February predictions compared to predictions initialized earlier
Fcsts Initiated: Dec.12-21,2011
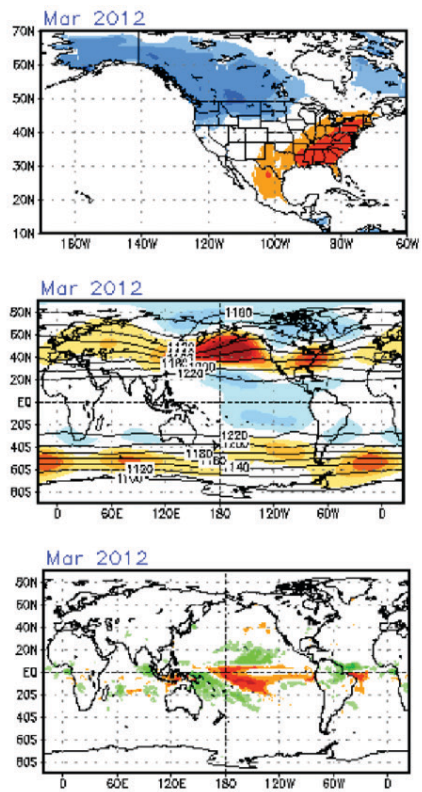

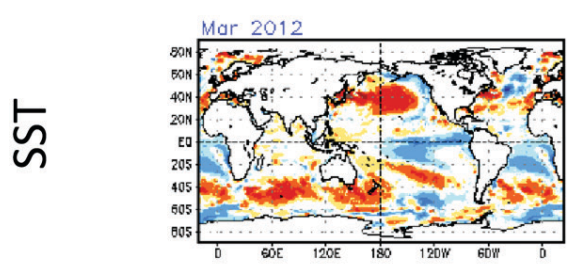

Fcsts Initiated: Jan.12-21,2012
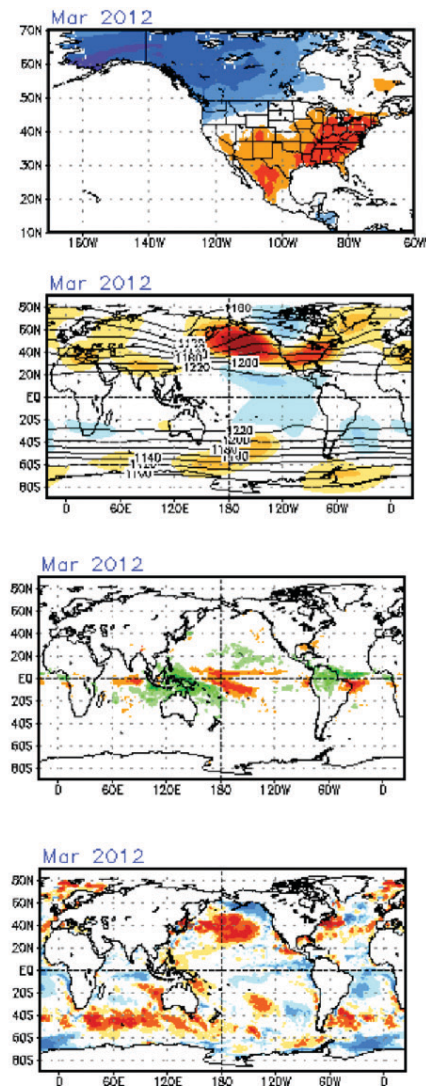

Fcsts Initiated: Feb.1-10, 2012

\section{$\sum_{0}$}

FIG. 8. Operational ensemble-mean CFSv2 forecasts verifying Mar 2012 based on initializations during (left) I2-2I Dec 20II, (middle) I2-2I Jan 20I2, and (right) I- 10 Feb 20I2. Predictions are for (top) surface temperature anomalies [first interval $0.5^{\circ} \mathrm{C}, 1^{\circ} \mathrm{C}$ intervals thereafter; warm (cold) anomalies in red (blue)], (second row) $200-\mathrm{hPa}$ heights [total field contoured, anomalies shaded every $15 \mathrm{~m}$; positive (negative) anomalies in red (blue)], (third row) precipitation anomalies [first interval I $\mathbf{~ m m ~ d a y ~}{ }^{-1}, 2 \mathbf{~ m m ~ d a y ~}^{-1}$ intervals thereafter; wet (dry) anomalies in green (red)], and (bottom) sea surface temperature anomalies [intervals are $0.25^{\circ}, 0.5^{\circ}, 1.0^{\circ}$, and $2.0^{\circ} \mathrm{C}$; warm (cold) anomalies in red (blue)]. Predictions are made four times daily, yielding a $40-\mathrm{member}$ ensemble for each 10 -day period. All anomalies are defined relative to CFSv2 lead time-dependent Mar hindcast climatologies for 1982-2010. 
indicates that specific conditions emergent in early February, most likely in the atmospheric initial state, substantially increased the probability of extreme warm temperatures in March over the central and eastern United States and led to a predicted pattern of anomalies closer to what was observed. This provided important additional information beyond the long-term trend and seasonal-to-interannual climate variations on the heightened potential for extreme warm conditions over the United States in March, including the timing and spatial pattern of temperature anomalies. The Climate Prediction Center capitalized on this "forecast of opportunity" to anticipate the monthly temperature pattern very well, achieving the highest skill score on record for their March 2012 forecast (Heidke skill score of +76)

a) March 2012 Temperature: GFS 50 Member Ensemble

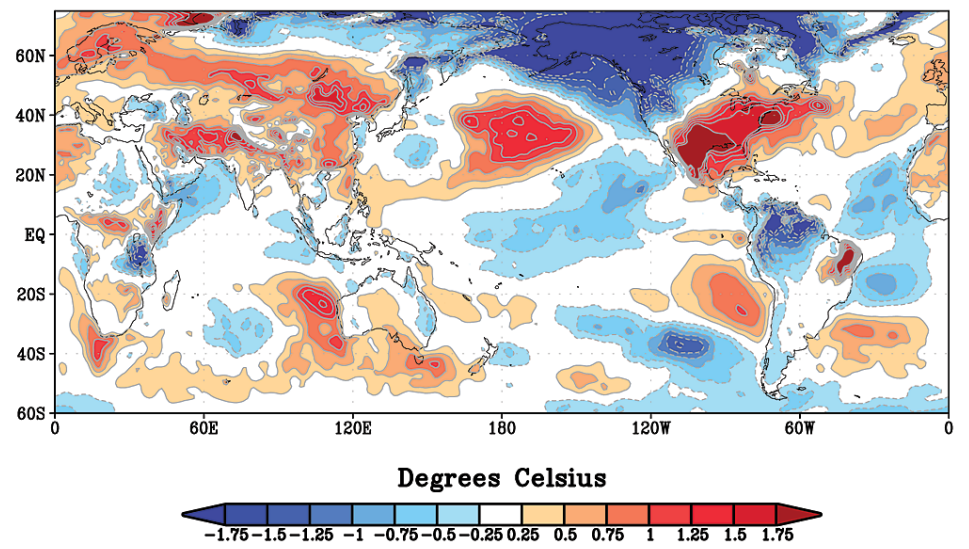

b) March $2012300 \mathrm{hPa}$ : GFS 50 Member Ensemble

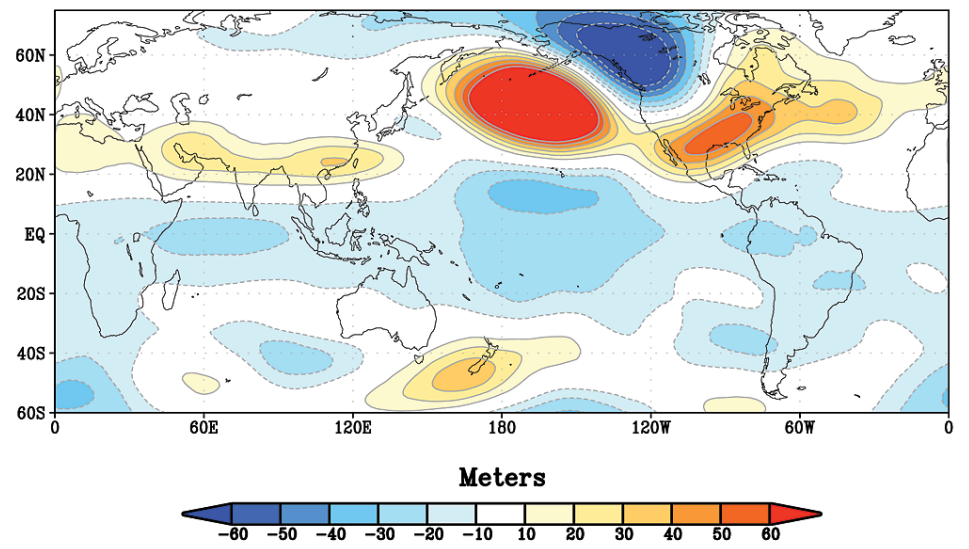

FIG. 9. Mar 2012 simulated (top) 2-m air temperature anomalies $\left({ }^{\circ} \mathrm{C}\right)$ and (bottom) $300-\mathrm{hPa}$ height anomalies $(\mathrm{m})$. Simulations are from the NCEP GFSv2 model forced by observed sea surface temperature, sea ice, and carbon dioxide concentrations. Plots show the 50-member ensemble average, where anomalies are relative to the model's 198I-2010 climatology. in their mid-February issued prediction ( $w w w . c p c$ .ncep.noaa.gov/products/predictions/long_range tools/briefing/mon_veri.grid.php).

The contributions from various time scales can be seen when comparing CFS ensemble forecasts for March 2012 initialized from longer to shorter lead times for a large region $\left(30^{\circ}-50^{\circ} \mathrm{N}, 110^{\circ}-80^{\circ} \mathrm{W}\right)$ encompassing the region affected by very warm temperatures (Fig. 10). Comparing the model climatological distribution (dashed black line) with the distribution of ensemble forecasts initialized 250-269 days before (blue line), at approximately 8 to 9 months lead time there is a slight shift in the distribution toward warm conditions over the central United States but no clear evidence of an increase in the probability of warm extremes. At approximately 6 months lead time (orange curve), a larger warm signal together with an increased probability of warm extremes appears in association with the emergence of the wintertime SST pattern in the coupled model predictions. This signal continues through the winter, with some further increase in the probability of warm extremes for forecasts initialized in late January (green curve). Forecasts initialized in late February (red curve) then show a large increase in the probability of above normal temperatures and, in particular, a greatly enhanced risk of extremely warm conditions in March.

DISCUSSION. Extreme warmth covered much of the United States in March 2012, with maximum temperature departures centered over the upper Midwest. While March 2012 was exceptional, it had historical precedent in an event that occurred over a century earlier. March 1910 was nearly as extreme as in 2012, differing in contiguous U.S. monthly-mean temperatures by only $0.3^{\circ} \mathrm{C}$. The two months also showed considerable resemblance in many features around the globe. The 1910 March event, which originated from natural climate variability, was sufficiently long ago to be beyond the experience of almost all of those living today, although it is still 
studied because of its profound relevance for wildfire management (Diaz and Swetnam 2013). This earlier extreme event serves as an important reminder that individual human lifetimes (and even observational records) are often too short to gauge the full range of natural climate variability. This suggests a need for caution in attributing a rare event to human causes simply because it has occurred recently. Rarity alone does not imply a particular cause, and careful analysis is required to identify the roles of various factors that can make an event extreme.

In a global context, the exceptional warmth over the United States in March 2012 was a regional extreme event that occurred within an overall warming climate in which the global-mean surface temperature was $0.46^{\circ} \mathrm{C}$ above the twentieth-century average. Overall, we found that the superposition of a strong natural variation comparable to March 1910 together with a long-term regional warming of approximately $1^{\circ} \mathrm{C}$ would be sufficient to account for the extreme magnitude of the March 2012 temperature anomalies. This suggests that a nonlinear response to climate change is not required to explain either the occurrence or exceptional magnitude of this event.

The exceptional warmth of March 2012 was a transient event. Daily mean temperatures reached values of $15^{\circ}-20^{\circ} \mathrm{C}$ or more above normal during the event's peak, which extended over a period of approximately two weeks beginning in the second week of March. Vigorous and sustained poleward heat transports combined with quasi-adiabatic vertical mixing provided the proximate cause for the extreme temperatures. The exceptional magnitude of the temperature anomalies can be largely accounted for by the nearly horizontal transport of sensible heat from climatologically warmer regions near the Gulf of Mexico poleward to north of the Canadian border. The March warmth was therefore strongly dominated by dynamical processes. This distinguishes this early spring warm extreme from many sustained summertime heat waves (e.g., Lyon and Dole 1995; Mueller and Seneviratne 2012; Hoerling et al. 2013) where anomalous local radiative forcing and land surface feedbacks associated with droughts have been shown to play first-order roles. While snow cover loss that occurred in conjunction with the March 2012 event likely contributed to the extreme warmth in the northern Midwest, much of the area affected by very high temperatures does not normally have snow cover by mid-March.

Both seasonal-to-interannual and intraseasonal climate variations provided important contributions to this extreme event, with multiple indications for connections to natural patterns of tropical variability.

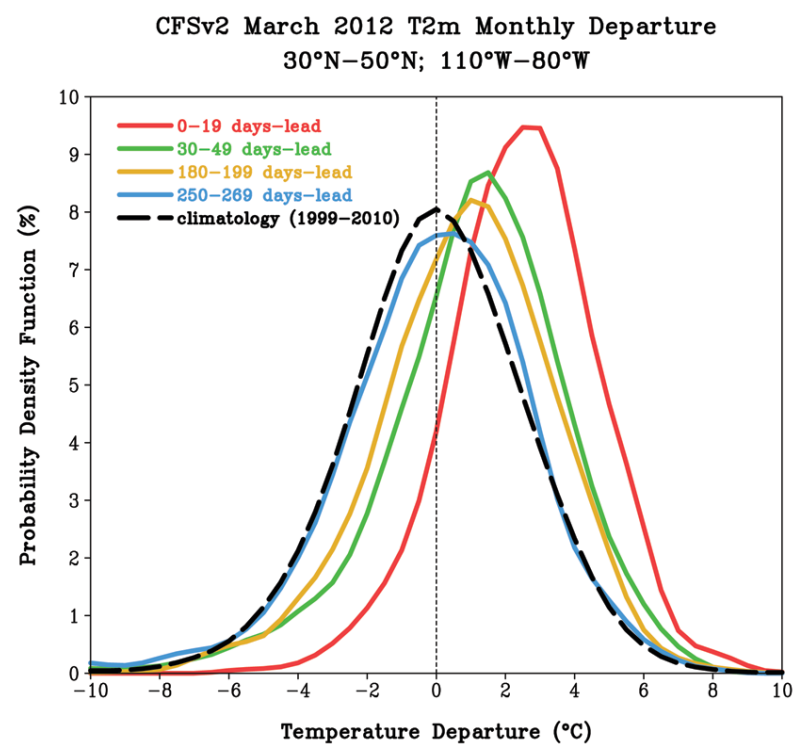

FIG. 10. The probability distribution functions (PDFs) of 2-m air temperature monthly anomalies for Mar 2012 derived from CFSv2 model predictions at different lead times (colored curves) and for a Mar climatological distribution of hindcasts (dashed black curve). All prediction PDFs are derived from $\mathbf{8 0}$-member ensembles, while the climatological PDF is derived from all Mar hindcasts (retrospective forecasts) up to 6 months in advance over the years 1999-2010 (1728 members). Anomalies are defined relative to the CFSv2 hindcast climatologies for 1982-2010, as in Fig. 8. Predictions are averaged for the region $30^{\circ}-50^{\circ} \mathrm{N}, 110^{\circ}-80^{\circ} \mathrm{W}$.

NCEP CFS model ensemble predictions for March 2012 initialized the previous December and January consistently showed an increased likelihood of warm conditions over the eastern United States, largely as a response to anomalous SSTs. Predictions initialized in February had several similar features, but also key differences, showing a substantial increase in the probability for an exceptionally warm March over the central and eastern United States. This provided evidence that specific conditions emergent in early February, most likely in the atmospheric initial state, played a major role in this extreme event. Observational and model results showed that the development of an exceptionally strong MJO in February was of central importance, forcing an extratropical wave train similar to the observed circulation anomalies during the period in which the event was most extreme. This strong MJO increased the likelihood of extreme warm temperatures over the region during March and provided a bridge linking climate and weather phenomena and predictions (Zhang 2013).

We also found that monthly temperature variability has declined substantially since the beginning of 
the twentieth century in parts of the upper Midwest affected by the extreme warmth. Such a decline has important implications. It would lead to an expectation for fewer extreme events of either sign (Katz and Brown 1992; Sardeshmukh et al. 2000). In particular, declining variability would lead to a reduced probability of warm extremes compared to what would be expected from a mean warming trend alone, as well as to a relatively faster decrease in the probability of cold extremes. Thus, in this region estimates of changes in the probability of monthly-mean temperature extremes based on the mean warming trend alone may contain significant errors, with a bias toward overestimating the likelihood of warm extremes and underestimating the rate of decrease in cold extremes. The large change in monthly temperature variability over the twentieth century also indicates that $30-\mathrm{yr}$ periods are too short to obtain reliable climatological estimates of monthly-mean variance. This suggests that estimated frequencies of monthly or seasonal extremes derived from the mean and variance of 30 -yr base periods (e.g., Hansen et al. 2012) should be interpreted with great caution.

PUTTING THE PIECES TOGETHER. Synthesizing our observational and model results, Fig. 11 illustrates schematically how multiple pieces from longer-term climate trends to shorter-term weather and climate variations came together to produce the extreme warm temperatures over the United States in March 2012. A long-term March warming trend

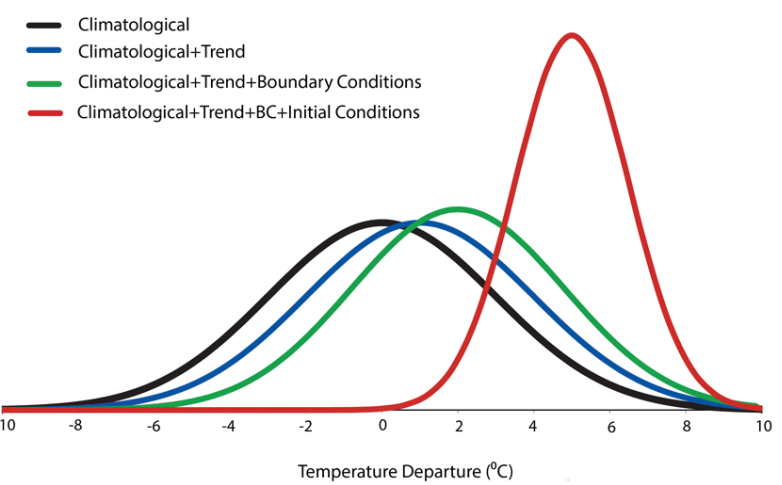

FIG. II. A schematic representation of how predictions for the March 2012 PDF shifted away from the climatological distribution (black) in response to different factors. These include long-term trends and multidecadal variations that evolve on time scales much longer than a season (blue), SSTs and other boundary forcings varying on seasonal-to-interannual time scales (green), and the MJO and other shorter time-scale phenomena dominated by atmospheric processes varying on subseasonal-to-daily time scales (red). shifted the temperature probability distribution to the right (blue curve) from the climatological distribution (black curve) by approximately $1^{\circ} \mathrm{C}$, increasing the probability of above normal temperatures and warm extremes. The addition of specific boundary conditions for $2011 / 12$, especially related to tropical sea surface temperature anomalies, increased this probability further (green curve). The large shift in the distribution in early February associated with an MJO event (red curve) indicated a substantially increased potential for an extremely warm March and provided important additional predictive information on the timing and spatial pattern of temperature anomalies. Thus, several pieces from climate to weather ultimately linked together favorably to make the observed March 2012 extreme event. However, even at lead times of a few weeks extreme warm temperatures were far from certain. As the width of the distributions indicates, a large range of outcomes was possible, and what occurred could well have been otherwise.

The spread in the distributions is largely a manifestation of internal atmospheric variations, including low-frequency variations like the Pacific-North American (PNA) pattern, synoptic-scale phenomena, and interactions between synoptic-scale disturbances and the more slowly evolving flow. Such atmospheric variations can amplify or dampen the forced response. Our results indicate that in this case they augmented the response, contributing substantially to the extreme warmth in this case. Thus, a full explanation for the exceptional warmth of March 2012 must also consider these fast phenomena and dynamical processes, some but not all of which have been described in this study, although their predictability is typically limited to time scales of a few weeks or less.

Overall, our results indicate that the extreme magnitude of the March 2012 temperature anomalies can be largely explained by natural variability, with an additional contribution from a long-term warming trend of approximately $1^{\circ} \mathrm{C}$ that is likely mostly due to human influences. Phenomena evolving on interannual, intraseasonal, and synoptic weather time scales were key factors in making this event extreme. Increased understanding of the connections between climate and weather, and especially the implications for anticipating future extreme events, will be essential for meeting many societal needs, from improving early warning on potential disasters to providing information needed for longer-term adaptation to a changing climate. Toward this end, large ensembles developed for climate change projections and initialized weather and climate predictions, as used in this study, have become increasingly valuable for 
identifying how phenomena and processes across the temporal spectrum from climate to weather contribute to make an extreme event. Such knowledge will be essential for improving our ability to better anticipate future extremes in a variable and changing climate. In particular, to increase confidence in future projections, our results reinforce the necessity for climate models to simulate with fidelity modes of natural variability on intraseasonal-to-interannual time scales that can be of fundamental importance for producing extreme events, as in this case. While advances have been impressive, there remain major opportunities for further progress (Shapiro et al. 2010). We still have much to learn.

ACKNOWLEDGMENTS. The authors thank two anonymous reviewers for their helpful comments on the manuscript. This study was supported by NOAA's Climate Program Office.

APPENDIX A: LINEAR BAROCLINIC MODEL. The LBM is a time-dependent atmospheric model based on the primitive equations. The model consists of five basic equations describing vorticity, divergence, temperature, mass, and hydrostatic balances. The model is global with a T21 spherical harmonic horizontal resolution and 10 equally spaced pressure levels. There is no topography at the lower boundary. The model is linearized about a three-dimensional time-mean March basic state over 1981-2010 and forced by a couplet of diabatic heating with a positive maximum centered at $5^{\circ} \mathrm{S}, 100^{\circ} \mathrm{E}$ and negative maximum at $5^{\circ} \mathrm{S}, 170^{\circ} \mathrm{E}$, which is designed to mimic the anomalous rainfall pattern observed over the Indian Ocean and western Pacific Ocean during the first half of March 2012. Additional experiments indicate that the results are not sensitive to the precise choice of locations of the maxima within the same general regions described above.

The specified heating anomalies have maximum values of $2.5 \mathrm{~K} \mathrm{day}^{-1}$ at $350 \mathrm{hPa}$. Perturbations from the basic state are interpreted as the linear model response to the specified forcing. Rayleigh friction and Newtonian damping are given the rate of $(1 \text { day })^{-1}$ at the lowest level, decreasing linearly to zero at $700 \mathrm{hPa}$. A biharmonic diffusion with a coefficient of $2 \times 10^{16} \mathrm{~m}^{4} \mathrm{~s}^{-1}$ is applied in the vorticity, divergence, and thermodynamic equations. These levels of dissipation are sufficient to stabilize the model so that a steady state can be reached. A thermal diffusion with a coefficient of $2 \times 10^{6} \mathrm{~m}^{2} \mathrm{~s}^{-1}$ is added to represent the eddy effects. We approximate the steady solution as the average of the last 5 days of a 60 -day integration.
APPENDIX B: GFS MODEL EXPERIMENTS. To estimate the atmospheric response to observed boundary conditions for the March 2012 event, ensemble model simulations forced by specified observed boundary conditions were performed with the NOAA/NCEP GFSv2-the atmospheric component of the CFSv2 model used for operational predictions. Such boundary-forced atmospheric model simulations are often referred to as Atmospheric Model Intercomparison Project (AMIP) experiments. Atmospheric model integrations were conducted over the period from January 1979 to December 2012. Time-varying SSTs, sea ice, and $\mathrm{CO}_{2}$ concentrations were specified from observed conditions over the period based on monthly analyses. Other greenhouse gases (e.g., $\mathrm{CH}_{4}, \mathrm{NO}_{2}, \mathrm{O}_{3}$, and $\mathrm{CFCs}$ ), aerosols, solar, and volcanic aerosols were set to climatological values. A 50-member ensemble was constructed with identical external boundary conditions specified for each member, with each member differing only by its initial atmospheric conditions in January 1979. The atmospheric model simulations were performed at T126 $(\sim 100 \mathrm{~km})$ horizontal resolution with 64 vertical levels. The systematic response to the time-evolving forcings was determined from the ensemble mean of the 50 ensemble members.

\section{REFERENCES}

Allen, B., cited 2012: Hard freeze hurts Michigan cherry crop. The Environment Report, Michigan Radio. [Available online at www.environmentreport.org /show.php?showID=629.]

Brunet, G., and Coauthors, 2010: Collaboration of the weather and climate communities to advance subseasonal-to-seasonal prediction. Bull. Amer. Meteor. Soc., 91, 1397-1406.

Cattiaux, J., R. Vautard, C. Cassou, P. Yiou, V. MassonDelmotte, and F. Codron, 2010: Winter 2010 in Europe: A cold extreme in a warming climate. Geophys. Res. Lett., 37, L20704, doi:10.1029/2010GL044613.

Compo, and Coauthors, 2011: The Twentieth Century Reanalysis Project. Quart. J. Roy. Meteor. Soc., 137, 1-28, doi:10.1002/qj.776.

Diaz, H. F., and T. W. Swetnam, 2013: The wildfires of 1910: Climatology of an extreme early twentiethcentury event and comparison with more recent extremes. Bull. Amer. Meteor. Soc., 94, 1361-1370.

Dole, E. M., M. Hoerling, and S. Schubert, Eds., 2008: Reanalysis of historical climate data for key atmospheric features: Implications for attribution of causes of observed change. U.S. Climate Change Science Program and the Subcommittee 
on Global Change Research Rep., NOAA/NCDC, $156 \mathrm{pp}$.

Elwood, E. R., S. A. Temple, R. B. Primack, N. L. Bradley, and C. C. Davis, 2013: Record-breaking early flowering in the eastern United States. PLoS ONE, 8, e53788, doi:10.1371/journal.pone.0053788.

Hansen, J., M. Sato, and R. Ruedy, 2012: Perception of climate change. Proc. Natl. Acad. Sci. USA, 109, 14726-14727.

Hegerl, G. C., and Coauthors, 2007: Understanding and attributing climate change. Climate Change 2007: The Physical Science Basis, S. Solomon et al., Eds., Cambridge University Press, 663-745.

Hoerling, M., and Coauthors, 2013: Anatomy of an extreme event. J. Climate, 26, 2811-2832.

Hoskins, B. J., and D. J. Karoly, 1981: The steady linear response of a spherical atmosphere to thermal and orographic forcing. J. Atmos. Sci., 38, 1179-1196.

Kalnay, E., and Coauthors, 1996: The NCEP/NCAR 40-Year Reanalysis Project. Bull. Amer. Meteor. Soc., 77, 437-470.

Karoly, D. J., R. A. Plumb, and M. Ting, 1989: Examples of the horizontal propagation of quasi-stationary waves. J. Atmos. Sci., 46, 2802-2811.

Katz, R. W., and B. G. Brown, 1992: Extreme events in a changing climate: Variability is more important than averages. Climatic Change, 21, 289-302.

Liebmann, B., and C. A. Smith, 1996: Description of a complete (interpolated) outgoing longwave radiation dataset. Bull. Amer. Meteor. Soc., 77, 1275-1277.

Linkin, M. E., and S. Nigam, 2008: The North Pacific Oscillation-west Pacific teleconnection pattern: Mature-phase structure and winter impacts. J. Climate, 21, 1979-1997.

Lyon, B., and R. M. Dole, 1995: A diagnostic comparison of the 1980 and 1988 U.S. summer heat wavedroughts. J. Climate, 8, 1658-1675.

Mantua, N. J., S. R. Hare, Y. Zhang, J. M. Wallace, and R. C. Francis, 1997: A Pacific interdecadal climate oscillation with impacts on salmon production. Bull. Amer. Meteor. Soc., 78, 1069-1079.

Meehl, G. A., C. Tebaldi, G. Walton, D. Easterling, and L. McDaniel, 2009: Relative increase of record high maximum temperatures compared to record low minimum temperatures in the U.S. Geophys. Res. Lett., 36, L23701, doi:10.1029/2009GL040736.

Mueller, B., and S. I. Seneviratne, 2012: Hot days induced by precipitation deficits at the global scale. Proc. Natl. Acad. Sci. USA, 109, 12 398-12403.

Otto, F. E. L., N. Massey, G. J. van Oldenborgh, R. G. Jones, and M. R. Allen, 2012: Reconciling two approaches to attribution of the 2010 Russian heat wave. Geophys. Res. Lett., 39, L04702, doi:10.1029/2011GL050422.

Ouzeau, G., J. Cattiaux, H. Douville, A. Ribes, and D. Saint-Martin, 2011: European cold winter 2009-2010: How unusual in the instrumental record and how reproducible in the ARPEGEClimat model? Geophys. Res. Lett., 38, L11706, doi:10.1029/2011GL047667.

Peng, S., and J. S. Whitaker, 1999: Mechanisms determining the atmospheric response to midlatitude SST anomalies. J. Climate, 12, 1393-1408.

Plumb, R. A., 1985: On the three-dimensional propagation of stationary waves. J. Atmos. Sci., 42, 217-229.

Reynolds, R. W., N. A. Rayner, T. M. Smith, D. C. Stokes, and W. Q. Wang, 2002: An improved in situ and satellite SST analysis for climate. J. Climate, 15, 1609-1626.

Saha, S., and Coauthors, 2013: The NCEP Climate Forecast System Version 2. J. Climate, in press, doi:10.1175/JCLI-D-12-00823.1.

Sardeshmukh, P. D., G. P. Compo, and M. C. Penland, 2000: Changes of probability associated with El Niño. J. Climate, 13, 4268-4286.

Shapiro, M., and Coauthors, 2010: An Earth-system prediction initiative for the twenty-first century. Bull. Amer. Meteor. Soc., 91, 1377-1388.

Simmons, A. J., J. M. Wallace, and G. W. Branstator, 1983: Barotropic wave-propagation and instability, and atmospheric teleconnection patterns. J. Atmos. Sci., 40, 1363-1392.

Smith, T. M., R. W. Reynolds, T. C. Peterson, and J. Lawrimore, 2008: Improvements to NOAA's historical merged land-ocean surface temperature analysis (1880-2006). J. Climate, 21, 2283-2296.

Stott, P. A., D. A. Stone, and M. T. Allen, 2004: Human contribution to the European heatwave of 2003. Nature, 432, 610-614.

Taylor, K. E., R. J. Stouffer, and G. A. Meehl, 2012: An overview of CMIP5 and the experiment design. Bull. Amer. Meteor. Soc., 93, 485-498.

Wheeler, M., and H. Hendon, 2004: An all-season realtime multivariate MJO index: Development of an index for monitoring and prediction. Mon. Wea. Rev., 132, 1917-1932.

Wolter, K., and M. S. Timlin, 2011: El Niño/Southern Oscillation behaviour since 1871 as diagnosed in an extended multivariate ENSO index (MEI.ext). Int. J. Climatol., 31, 1074-1087.

Zhang, C., 2013: Madden-Julian oscillation: Bridging weather and climate. Bull. Amer. Meteor. Soc., 94, 1849-1870. 